\title{
Errata
}

\section{Erratum: Self-consistent relativistic calculation of nucleon mean free path} [Phys. Rev. C 48, 1062 (1993)]

\author{
G. Q. Li, R. Machleidt, and Y. Z. Zhuo
}

PACS number(s): $21.65 .+\mathrm{f}, 99.10 .+\mathrm{g}$

Figure 3(a) is wrong. The correct Fig. 3(a) is given here. The other parts of Fig. 3 are correct. The mean free path was calculated with the correct real $U_{S}$ as displayed in the corrected figure.

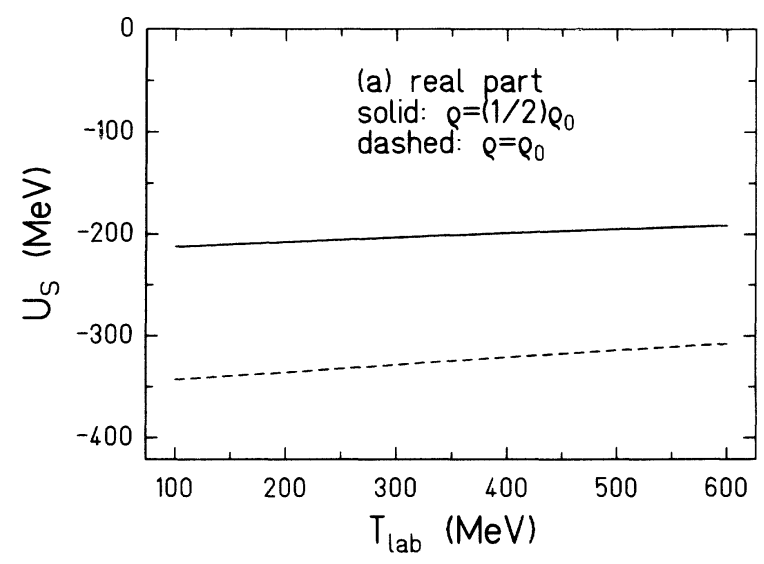

